\title{
Penilaian Resiko Kejahatan Illegal Content Menggunakan Framework Nist 800-30
}

\author{
Ahmad Marsehan ${ }^{1}$, Muhammad Izman Herdiansyah ${ }^{2}$, Ahmad Haidar Mirza ${ }^{3}$, Darius Antoni ${ }^{4}$ \\ ${ }^{1}$ Magister Teknik Informatika \\ e-mail: benijaman@gmail.com
}

${ }^{2,3,4}$ Teknik Informatika Universitas Bina Darma

\begin{abstract}
Abstrak - Pada era sekarang ini, penyebaran informasi cenderung lebih mudah dilakukan, hal ini disebabkan oleh perkembangan teknologi internet dan smartphone yang menyebabkan setiap orang bertindak sebagai pengirim dan penerima berita tanpa harus tersaring. Hal ini tentunya akan menimbulkan permasalahan baru, terutama potensi pelanggaran hukum atau tindak pidana UU ITE seperti konten ilegal. Untuk mengatasi hal tersebut perlu diterapkan manajemen risiko siber sehingga risiko siber pada aspek konten ilegal dapat dikelola. Berdasarkan penelitian yang dilakukan dengan menggunakan Kerangka NIST 800-30 pada beberapa siswa di Kota Lubuklinggau, perilaku atau tindakan yang biasanya dilakukan terkait penanganan penyebaran informasi di media sosial atau internet adalah pada aspek tidak memahami perbedaan informasi. berisi konten ilegal dan kurangnya pemahaman tentang konsekuensi hukum. Dalam menyebarkan informasi konten ilegal di media sosial termasuk dalam kategori risiko tinggi, selanjutnya ketidakmampuan masyarakat untuk menilai keandalan dan kesenangan berbagi informasi tanpa mengetahui kredibilitas informasi tersebut termasuk dalam kategori risiko sedang, dan akhirnya siswa senang untuk membaca informasi kontroversial meskipun informasi tersebut tidak jelas kredibilitasnya termasuk dalam kategori risiko rendah
\end{abstract}

Kata Kunci : Analisa Resiko, Konten Ilegal, NIST 800-30

\begin{abstract}
In the current era, information dissemination tends to be easier to do, this is due to the development of the internet and smartphone technology, which causes everyone to act as a sender and receiver of news without having to be filtered. This will certainly lead to new problems, especially potential violations of the law or criminal acts of the ITE Law such as illegal content. To overcome this, it is necessary to apply cyber-risk management so that cyber risks in the aspect of illegal content can be managed. Based on research conducted using the NIST 800-30 Framework on several students in Lubuklinggau City, the behavior or actions that are usually carried out related to handling the dissemination of information on social media or the internet are in the aspect of not understanding differences in information containing illegal content and lack of understanding of legal consequences. in disseminating illegal content information on social media it is included in the high risk category, furthermore the inability of the public to assess the reliability and pleasure of sharing information without knowing the information's credibility falls into the medium risk category, and finally students are happy to read controversial information even though the information is not clearly its credibility is included in the low risk category.
\end{abstract}

Keywords: Risk Analys, Ilegal Content, NIST 800-30

\section{PENDAHULUAN}

Kemajuan teknologi informasi menimbulkan tantangan yang kompleks untuk para masyarakat. Kemajuan teknologi informasi sekarang ini menyebabkan hampir semua aspek menjadi serba digital membawa mampu orang ke dunia bisnis yang revolusioner (digital revolution era) karena dirasakan lebih mudah, murah, praktis dan dinamis memperoleh informasi. Dilain sisi berkembang teknologi informasi menimbulkan aspek negatif sampai tahap mencemaskan dengan kekhawatiran pada perkembangan tindak pidana di bidang teknologi informasi yang berhubungan dengan "cybercrime" atau kejahatan dunia maya (Raodia, 2019) Ada banyak jenis cybercrime seperti Ilegal Contents ,Data Forgery, Cyber Espionage, Cyber
Sabotage and Extortion dan masih banyak lagi. (Abidin, 2015)

Cyber Crime sendiri merupakan tindakan kriminalitas yang memanfaatkan teknologi komputer sebagai alat kejahatan utama. Di era sekarang ini seseorang ingin mengetahui informasi tentang berbagai peristiwa, pendapat maupun berita yang berada di sekitar maupun dibelahan dunia untuk dapat diakses lebih mudah, terlebih lagi dengan menggunakan teknologi smartphone. (Danuri and suharnawi, 2018). Tidak adanya ketelitian menyebabkan orang kurang memperhatikan informasi yang sedang di baca atau di peroleh dan menyangka sesuatu buruk seolah tidak akan menimpa sampai kemudian dirinya sendiri menjadi korban. Ketidakpedulian inilah 
menyebabkanturunnya tingkat kesadaranakan keamanan serta kewaspadaaan.

Dalam penelitian ini, penulis melakukan observasi terhadap pengguna smartphone pada kalangan masyarakat seperti : pegawai negeri sipil, mahasiswa al-azhar, karyawan swasta, pelajar sma dan pelajar smp. Masyarakat sebagai konsumen informasi bisa dilihat masih belum bisa membedakan mana informasi yang benar dan mana informasi yang palsu.

Penyampaian informasi tidak hanya memberikan dampak positif tetapi ada juga memberikan dampak yang kurang baik (negatif). Penyampaian informasi begitu cepat dimana setiap orang dengan mudah mendapatkan,memproduksi bahkan melakukan penyebaran informasi melalui medai sosial. Media sosial telah menjadi wadah atau sarana komunikasi yang dapat menyampaikan pesan / informasi secara efektif karena dapat di jangkau oleh pengguna media sosial dan juga media sosial dapat memudahkan individu maupun kelompok / organisasi berkomunikasi (Ratnamulyani and Maksudi, 2018).

Informasi yang dikeluarkan oleh sekelompok orang maupun badan usaha melalui media elektronik telah terkirim dan di baca banyak orang dapat mempengaruhi tindakan seseorang atau kelompok. Sangat disayangkan jika informasi tersebut adalah informasi yang tidak akurat atau informasi hoax, yang dapat mengiring pengguna media informasi kepada opini yang negative (Rahadi, 2017).

Secara umum hoax adalah berita palsu yang tidak dapat dipertanggung jawabkan kebenarannya, dan berita palsu juga termasuk Illegal Content (Yulianita et al., 2017). Banyaknya masyarakat yang menggunakan media sosial dan mendapatkan informasi / berita palsu yang disebarkan langsung menjadikan peluang besar bagi masyarakat terpengaruh oleh berita palsu tersebut. Berita palsu dan pesan kebencian yang diterima masyarakat sering tanpa sadar diterima sebagai informasi yang benar dan ikut menyebarkan informasi tersebut.

Metode yang dipakai dalam penelitian ini menggunakan framework NIST, karena metode tersebut dirancang menghitung secara kuantitatif dan didasarkan pada analisa keamanan yang cukup sesuai untuk mengidentifikasi, mengevaluasi dan mengelola risiko dalam sistem TI. (Elanda and Tjahjadi, 2018)

Dalam tulisan ini peneliti menganalisis dan membahas pemahaman mahasiswa di Kota Lubuklinggau terhadap kejahatan illegal content seperti berita hoax dan ujaran kebencian di smarpthone untuk menggambarkan profil keadaan pengguna smartphone menggunakan framework NIST800-30.

\section{METODOLOGI PENELITIAN}

NIST (National Institute of Standard andTechnology) Special Publication (SP) 800-30, Panduan Manajemen Risiko untuk Sistem Teknologi Informasi yang merupakan standar Pemerintah Federal US. Metodologi ini terutama dirancang untuk menjadi suatu perhitungan kualitatif dan didasarkan pada analisa keamanan yang cukup sesuai dengan keinginan pemilik sistem dan ahli teknis untuk benar-benar mengidentifikasi, mengevaluasi dan mengelola risiko dalam sistem TI. Proses ini sangat komprehensif, meliputi segala sesuatu dari ancaman-sumber identifikasi untuk evaluasi berkelanjutan dan penilaian(Elanda and Tjahjadi, 2018b).

Metodologi NIST terdiri dari 9 langkah:

1. Langkah 1: Karakterisasi Sistem

Tahap pertama yaitu menentukan batas-batas dari sistem atau objek penelitian termasuk didalamnya sumber daya dan informasi.

2. Langkah 2: Identifikasi Ancaman

Menentukan potensi ancaman yang dapat menyebabkan kerusakan pada sistem, atas kemungkinan resiko dapat timbul terhadap ancaman yang ada.Sumber ancaman secara umum dapat dari alam, manusia, atau pertimbangan lingkungan.

3. Langkah 3: Identifikasi Kerentanan

Melakukan identifikasi terhadap kerawanan atau kemungkingan resiko yang dapat timbul.

4. Langkah 4: Analisis Pengendalian

Analisis terhadap resiko yang telah diidentifikasi untuk minimalisir atau menghilangkan kemungkinan-kemungkinan ancaman. Penentuan analisis pengendalian didasarkan pada hasil jawaban dari responden.

5. Langkah 5: Penentuan Kemungkinan

Menentukan bobot rangking terhadap potensi dari kerawanan.Faktoryang menjadi pertimbanganadalah ancaman (sumber dan kemampuan), sifat dari kerawanan serta keberadaan dan efektifitas.

6. Langkah 6: Analisis Dampak

Menentukan dampak negatif yang dihasilkan atau yang timbul dari ancaman yang ada.Penentuan ini dilakukan berdasarkan pada analisa yang dilakukan terhadap responden.Besaran peringkat dampak rendah (10), menengah (50), tinggi (100). Rujuk ke SP NIST 800-30 definisi rendah, menengah, dan tinggi.

7. Langkah 7: Penentuan Risiko

Penilaian tingkat risiko yang dilakukan berdasarkan pada tingkatan resiko dengan menggunakan kemungkinan resiko atau ancaman low, medium atau heigh dan dampak yang ditimbulkan berdasarkan low, medium atau heigh. Output- Resiko tingkat rendah 
(dengan nilai 1 s/d 10), menengah (diatas 10 s/d 50), atau tinggi (diatas $50 \mathrm{~s} / \mathrm{d}$ 100). Rujuk ke SP NIST 800-30 definisi rendah, menengah, dan tinggi.

8. Langkah 8: Rekomendasi Kontrol

Tahapan ini menilai kemungkinan yang dapat mengurangi atau menghilangkan risiko yang telah dikenali. kemungkinan yang direkomendasikan sebaiknya harus dapat mengurangi tingkat risiko.

9. Langkah 9: Hasil Dokumentasi

Pada tahap ini, dilakukan pengembangan laporan hasil penilaian risiko (sumber ancaman, kerawanan, risiko yangdinilai dan kontrol yang direkomendasikan).

Untuk memperjelas alur penelitian ini, penulsi membuat bagan penelitian seperti gambar di bawah ini :

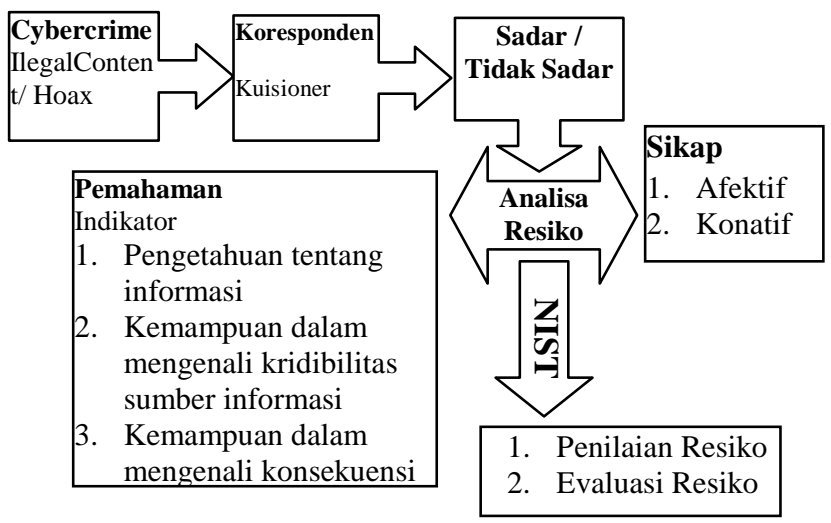

Gambar 1. Bagan Penelitian

\section{Pemahaman / Kesadaran}

Pemahaman atau kesadaran dalam penelitian ini diartikan sebagai tingkat pemahaman orang atau responden terhadap informasi dan juga berita yang mengandung konten ilegal seperti hoax. Tingkat pemahaman atau kesadaran dalam penelitian ini diukur menggunakan indikator sebagai berikut :

a. Pengetahuan tentang informasi atau berita yang mengandung ilegal content yang didefinisikan sebagai kemampuan seseorang atau responden dalam mengenali ciri khas informasi atau berita tersebut

b. Kridibilitas sumber diartikan sebagai kemampuan orang atau respoden dalam mengenali keaslian sumber informasi.

c. Memahami konsekuensi didefinisikan sebagai kemampuan orang atau responden dalam mengutip berita secara legal dan etis dan memahami konsekuensi penyebaran tak terbatas dari informasi.

\section{Sikap}

Sikap dalam penelitian ini dapat diartikan sebagai cara mahasiswa berpikir, merasakan dan bertindak terhadap beberapa aspek lingkungan serta konsep mental yang kompleks tentang proses motivasional, emosional, persepsi dan kognitif untuk mengevaluasi informasi yang mengandung kontek ilegal. Sikap terhadap informasi ilegal content dalam penelitian ini menggunakan pendekatan skala sikap dengan dimensi yaitu (Alatas et al., 2018)

a. Pendekatan Afektif yang merupakan pendekapan secara perasaan, emosi, atau ungkapan seseorang terhadap masalah atau objek yang dapat menjadi cara negatif atau positif yang dievaluasi dalam konteks kebutuhan seseorang. Dalam penelitian ini aspek afektif yaitu perasaan, emosi dan ungkapan orang atau responden terhadap terhadap informasi atau berita yang mengandung konten ilegal atau hoax

b. Pendekatan Perilaku (konatif) merupakan tindakan seseorang untuk bereaksi dengan cara tertentu terhadap objek berdasarkan pengetahuan dan perasaan yang dialami oleh responden. Dalam penelitian ini aspek konatif yaitu tindakan orang atau responden terhadap informasi atau berita yang mengandung konten ilegal atau hoax.

\section{Populasi}

Populasi merupakan keseluruhan objek atau fenomena yang diriset, Sedangkan sampel adalah sebagian dari keseluruhan objek atau fenomena yang akan diamati (Hikmat, 2011).

Berdasarkan hasil pengolahan dari kegiatan prasurvey yang dilakukan penulis maka didapatkan179 responden yang diberikan pertanyaan mengenai aktifitas bermedia sosial melalui handphone berikut jumlah sebaran responden yang digunakan berdasarkan profesi responsen.

Tabel 1 Data Sampel

\begin{tabular}{|l|c|}
\hline \multicolumn{1}{|c|}{ Masyarakat } & Jumlah \\
\hline Pegawai Negeri Sipil & 13 \\
\hline Mahasiswa Al-Azhar & 37 \\
\hline Karyawan Swasta & 95 \\
\hline Pelajar SMA & 23 \\
\hline Pelajar SMP & 11 \\
\hline Jumlah & $\mathbf{1 7 9}$ \\
\hline
\end{tabular}

\section{Variabel dan Indikator Penelitian}

Berdasarkan pada bagan pemikiran yang telah di jelaskan sebelumnya, maka peneliti dapat menentukan pernyataan yang akan di tanyakan berdasarkan pada 2 pendekatan yaitu 1) Pemahaman atau kesadaran mahasiswa terhadap berita yang mengandung konten ilegal, 2) sikap yang di lakukan oleh masyarakat ketika mendapatkan atau menerima informasi yang mengandung konten ilegal. Berikut indikator yang digunakan oleh penulis seperti terlihat pada tabel 2 dibawah ini. 
Tabel 2. Variabel dan Indikator Penelitian

\begin{tabular}{|c|c|c|c|}
\hline Variabel & Indikator & Pernyataan & Pengukuran \\
\hline \multirow{11}{*}{ Pemahaman } & \multirow{4}{*}{$\begin{array}{l}\text { Pengetahuan } \\
\text { tentang } \\
\text { Informasi }\end{array}$} & $\begin{array}{l}\text { Saya mampu untuk membedakan informasi apakah } \\
\text { termasuk berita / informasi yang mengandung hoax }\end{array}$ & Skala Likert \\
\hline & & $\begin{array}{l}\text { Saya dapat menjelaskan ciri-ciri berita / informasi yang } \\
\text { mengandung kontent illegal }\end{array}$ & Skala Likert \\
\hline & & $\begin{array}{l}\text { Saya menyertakan pengetahuan yang saya miliki dalam } \\
\text { merespon berita hoax yang disebarkan di media Sosial. }\end{array}$ & Skala Likert \\
\hline & & $\begin{array}{l}\text { Saya menyimpulkan pengetahuan yang diperoleh dari } \\
\text { kegiatan tersebut mengenai berita hoax yang disebarkandi } \\
\text { media sosial }\end{array}$ & Skala Likert \\
\hline & \multirow{5}{*}{$\begin{array}{c}\text { Bisa } \\
\text { mengenali } \\
\text { kredibilitas } \\
\text { informasi } \\
\text { yang ditemui }\end{array}$} & $\begin{array}{l}\text { Saya mempertanyakan kebenaran informasi atau berita } \\
\text { hoax tersebut saat membaca di media sosial }\end{array}$ & Skala Likert \\
\hline & & $\begin{array}{l}\text { Saya memeriksa kelengkapan informasi yang disebarkan } \\
\text { di media sosial }\end{array}$ & Skala Likert \\
\hline & & $\begin{array}{l}\text { Saya melakukan perbandingan terhadap informasi yang } \\
\text { disebarkan di media sosial dengan konteks dunia nyata }\end{array}$ & Skala Likert \\
\hline & & $\begin{array}{l}\text { Saya membandingkan informasi yang disebarkan dimedia } \\
\text { sosial dengan informasi dalam tautan situs/sumber } \\
\text { informasi yang tertera }\end{array}$ & Skala Likert \\
\hline & & $\begin{array}{l}\text { Saya membandingkan informasi pesan kebencian yang } \\
\text { didapat dari media sosial dengan informasi yang sama di } \\
\text { media lain }\end{array}$ & Skala Likert \\
\hline & \multirow[b]{2}{*}{$\begin{array}{c}\text { Mampu } \\
\text { memahami } \\
\text { konsekuensi } \\
\text { penyebaran } \\
\text { tak terbatas } \\
\text { informasi } \\
\text { dalam media } \\
\text { online. }\end{array}$} & Saya mencantumkan sumber saat menyebarkan informasi & Skala Likert \\
\hline & & $\begin{array}{l}\text { Saya memahami konsekuensi } \text { penyebaran sebuah } \\
\text { informasi di media sosial }\end{array}$ & Skala Likert \\
\hline \multirow{9}{*}{ Sikap } & \multirow{5}{*}{ Afektif } & $\begin{array}{l}\text { Senang mengetahui informasi / berita yang mengandung } \\
\text { konten ilegal }\end{array}$ & Skala Likert \\
\hline & & $\begin{array}{l}\text { Senang membaca informasi /berita yang mengandung } \\
\text { konten ilegal }\end{array}$ & Skala Likert \\
\hline & & $\begin{array}{l}\text { Benci mendengar informasi /berita yang mengandung } \\
\text { konten ilegal }\end{array}$ & Skala Likert \\
\hline & & $\begin{array}{l}\text { Penasaran dengan informasi /berita yang mengandung } \\
\text { konten ilegal }\end{array}$ & Skala Likert \\
\hline & & $\begin{array}{l}\text { Ingin tahu dengan informai / berita yang mengandung } \\
\text { konten ilegal }\end{array}$ & Skala Likert \\
\hline & \multirow{4}{*}{ Konatif } & $\begin{array}{l}\text { Suka berbagi informasi tentang pesan kebencian di media } \\
\text { sosial }\end{array}$ & Skala Likert \\
\hline & & Sering membicarakan tentang berita hoax & Skala Likert \\
\hline & & Tidak pernah menyebarkan informasi atau berita hoax & Skala Likert \\
\hline & & $\begin{array}{l}\text { Tidak akan menyebarkan informasi atau berita yang } \\
\text { mengandung hoax }\end{array}$ & Skala Likert \\
\hline
\end{tabular}

\section{HASIL DAN PEMBAHASAN}

Berdasarkan pada data pertanyaan quisioner yang telah diberikan ke seluruh responden maka, selanjutnya dilakukan pengolahan data dengan melakukan pengukuran likert dan hasilnya dihitung dengan rumus index\% dengan skala interval. Hasil dari skala likert yang dilakukan dapat dilihat pada tabel 3 .
Tabel 3. Tabel Skor Internal Likert

\begin{tabular}{|l|l|}
\hline Angka 0\% - & Sangat Tidak Setuju \\
$19,99 \%$ & \\
\hline Angka 20\% - & Tidak Setuju \\
$39,99 \%$ & \\
\hline Angka 40\% - & Netral \\
$59,99 \%$ & \\
\hline Angka 60\% - & Setuju \\
$79,99 \%$ & \\
\hline
\end{tabular}




\begin{tabular}{|l|l|}
\hline $\begin{array}{l}\text { Angka } 80 \%- \\
100 \%\end{array}$ & Sangat Setuju \\
\hline
\end{tabular}

Setelah didapatkan tabel skor internal likert, selanjutnya menghitung hasil dari respon responden berdasarkan jawaban pada kuisioner penelitian yang terdiri daripemahaman dan sikap.

Rata-rata hasil dari keseluruhan koresponden terhadappemahaman dan sikap dapat dilihat pada tabel di bawah ini :

Tabel 4. Rata-rata Perhitungan Pernyataan Keseluruhan Kuisioner

\begin{tabular}{|l|l|c|}
\hline \multicolumn{1}{|c|}{$\begin{array}{c}\text { Konponen } \\
\text { Sistem }\end{array}$} & \multicolumn{1}{|c|}{ Indikator } & Rata-rata \\
\hline Pemahaman & $\begin{array}{l}\text { Pengetahuan } \\
\text { Tentang } \\
\text { Informasi }\end{array}$ & 71,76 \\
\cline { 2 - 3 } & $\begin{array}{l}\text { Kemampuan } \\
\text { mengenali } \\
\text { kridibilitas } \\
\text { informasi }\end{array}$ & 75,47 \\
\cline { 2 - 3 } & $\begin{array}{l}\text { Kemampuan } \\
\text { dalam mengenali } \\
\text { konsekuensi }\end{array}$ & 66,76 \\
\hline Sikap & Afektif & 59,76 \\
\cline { 2 - 3 } & Konatif & 58,35 \\
\hline
\end{tabular}

\section{Pengukuran Resiko Dengan NIST 800-30}

Setelah hasil rata-rata keseluruhan perhitungan pernyataan kuisioner dilakukan, tahap selanjutnya melakukan 9 tahapan NIST SP 800-30. Berikut tahapan-tahapan yang dilakukan :

1. Karakteristik Sistem

Pada tahap ini terlihat karakterisktik ancaman dalam analisa resiko pada kasus cyber crime untuk content ilegal terdiri dari 2 kelompok yaitu pemahaman, dan sikap.

Tabel 5. Karakteristik Resiko Ilegal Content

\begin{tabular}{|l|l|}
\hline Konponen Sistem & \multicolumn{1}{|c|}{ Indikator } \\
\hline Pemahaman & $\begin{array}{l}\text { Pengetahuan Tentang } \\
\text { Informasi }\end{array}$ \\
\cline { 2 - 2 } & $\begin{array}{l}\text { Kemampuan mengenali } \\
\text { kridibilitas informasi }\end{array}$ \\
\cline { 2 - 2 } & $\begin{array}{l}\text { Kemampuan dalam } \\
\text { mengenali konsekuensi }\end{array}$ \\
\hline Sikap & Afektif \\
\cline { 2 - 2 } & Konatif \\
\hline
\end{tabular}

2. Identifikasi Ancaman

Sumber ancaman adalah keadaan atau peristiwa yang memiliki potensi menyebabkan kerusakan atau kesalahan. Untuk sumber ancaman dalam kasus ilegal konten dapat di definiskan atau digolongkan berdasarkan pada pernyataan di kuisioner yang telah disebarkan ke responden.

3. Identifikasi Kerentanan (Resiko)
Dari hasil kajian yang telah dilakukan bahwa tingkat kerentanan yang terbesar di hasilkan dari ketidakmampuan atau keengganan responen dalam mengenali kridibilitas informasi yang ditemui di media sosial, dimana artinya responden sering tidak melakukan perbandingan atau klarifikasi kebenaran akan informasi yang ditemui. Berikut merupakan hasil perhitungan rata-rata dari pernyataan kuisioner yang telah disebarkan.

Menurut (Gary Stoneburner et al., 2002)resiko merupakan dampak nyata yang dapat diukur secara kuantitatif dalam pendapatan yang hilang, biaya untuk memperbaiki, atau upaya untuk meperbaiki masalah yang disebabkan oleh ancaman. Selainitu, dampak lain dapat berupa hilangnya kepercayaan publik, hilangnya kridibilitas, serta kerusakan lainnya(Driantami, n.d.). Tingkat resiko dapat digambarkan berdasarkan pada tiga tingkatan yaitu :

Tabel 6. Tingkatan Resiko

\begin{tabular}{|c|c|c|}
\hline Ratting & Kriteria & Definisi \\
\hline $\mathrm{A}$ & High & 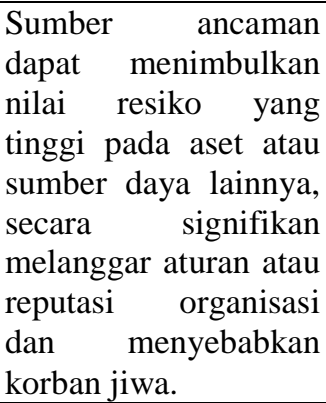 \\
\hline B & Medium & 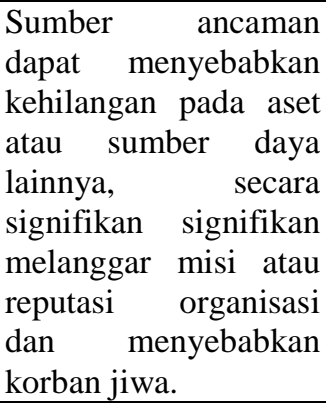 \\
\hline $\mathrm{C}$ & Low & $\begin{array}{lr}\text { Sumber } & \text { ancaman } \\
\text { dapat menyebabkan } \\
\text { nilai kehilangan pada } \\
\text { aset atau sumber daya, } \\
\text { secara rignifikan } \\
\text { signifikan melanggar } \\
\text { misi atau reputasi } \\
\text { organisasi }\end{array}$ \\
\hline
\end{tabular}

Dari uraian pada tabel 7 dapat didefinisikan tingkat kerentanan berdasarkan matrik level resiko yang terdiri dari 3 tingkatan yaitu Hight, Medium, Low. Tabel nya dapat dilihat dibawah ini :

Tabel 7. Tingkat Kerentanan

\begin{tabular}{|c|c|}
\hline $\begin{array}{c}\text { Tingkat } \\
\text { kerentanan }\end{array}$ & Karakteristik \\
\hline
\end{tabular}




\begin{tabular}{|c|c|}
\hline High & $\begin{array}{ll}- & \text { Mempunyai efek jangka } \\
& \text { panjang } \\
\text { - } & \text { Memiliki resiko melanggar } \\
& \text { hukum } \\
\text { - } & \text { Dapat dianggap Fitnah tau } \\
& \text { bohong }\end{array}$ \\
\hline Medium & $\begin{array}{l}\text { - Kurang kritis terhadap informasi } \\
\text { yang diterima } \\
\text { - Memungkinkan meningkatkan } \\
\text { jumlah ilegal konten di media } \\
\text { sosial }\end{array}$ \\
\hline Low & $\begin{array}{l}\text { - Kemungkinan terpancing / } \\
\text { terpovokasi }\end{array}$ \\
\hline
\end{tabular}

4. Analisa Pengendalian

Untuk mengetahui pengendalian yang digunakan dalam penanganan masalah kejahatan konten ilegal maka dilakukan analisa berdasarkan kuisioner yang telah disebarkan. Kuisioner ditujukan kepada responden yang merupakan masyarakat Kota Lubuklinggau. Berdasarkan analisa pengendalian didapatkan berupa kontrol untuk diteksi dan kontrol untuk pencegahan.

Tabel 8 Kontrol untuk diteksi

\begin{tabular}{|c|c|}
\hline Tahap & Kontrol \\
\hline $\begin{array}{c}\text { Diteksi } \\
\text { dan analisa }\end{array}$ & 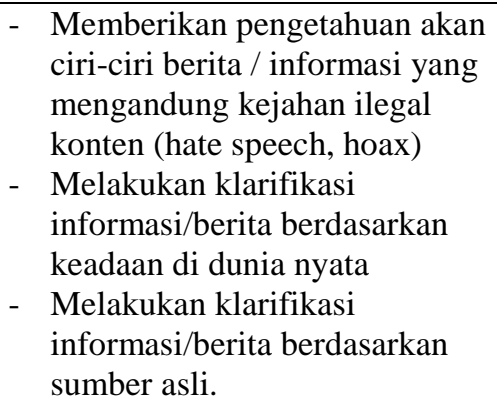 \\
\hline
\end{tabular}

Tabel 9. Kontrol untuk Pencegahan

\begin{tabular}{|c|c|}
\hline Tahap & Kontrol \\
\hline Pencegahan & 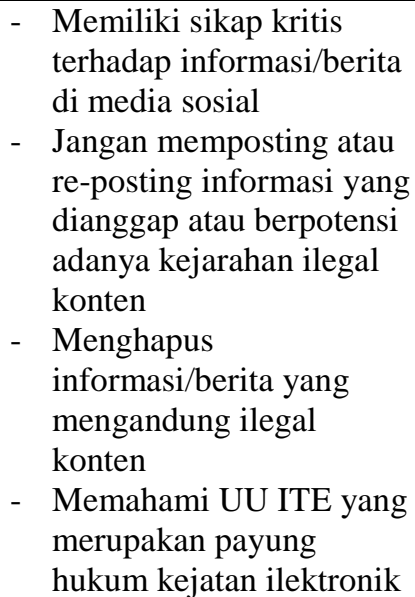 \\
\hline
\end{tabular}

4. Potensi Kemungkinan

Dibawah ini dilakukan analisis mengenai seberapa sering resiko yang telah disebutkan diatas akan terjadi. Penilaian aspek kemungkinan dilakukan berdasarkan perhitungan rata-rata dari likert yang telah diolah berdasarkan kuisioner yang disebarkan kepada responden. Berikut analisis dari potensi kemungkinan.merrujuk keSPNIST80030definisirendah, menengah, dan tinggi.

Tabel 10 Potensi Kemungkinan

\begin{tabular}{|c|c|c|c|c|}
\hline Variabel & Indikator & Tindakan & $\begin{array}{c}\text { Rata-rata } \\
\text { Skor }\end{array}$ & $\begin{array}{c}\text { Kemungki } \\
\text { nan }\end{array}$ \\
\hline \multirow[t]{5}{*}{ Pemahaman } & \multirow[t]{3}{*}{$\begin{array}{l}\text { Pengetahuan } \\
\text { Tentang } \\
\text { Informasi }\end{array}$} & $\begin{array}{l}\text { Ketidakmampuan dalam membedakan } \\
\text { informasi/berita yang mengandung ilegal } \\
\text { konten }\end{array}$ & \multirow[t]{3}{*}{71.76} & \multirow[t]{3}{*}{ High } \\
\hline & & $\begin{array}{l}\text { Tidak menyertakan sumber dalam } \\
\text { merespon berita yang mengandung ilegal } \\
\text { konten }\end{array}$ & & \\
\hline & & $\begin{array}{l}\text { Tidak menyertakan pengetahuan yang } \\
\text { didapat dalam menyikapi informasi / berita } \\
\text { ilegal konten }\end{array}$ & & \\
\hline & $\begin{array}{l}\text { Kemampuan } \\
\text { mengenali } \\
\text { kridibilitas } \\
\text { informasi }\end{array}$ & $\begin{array}{l}\text { Tidak mempertanyakan kebenaran } \\
\text { informasi dengan membandingkan antara } \\
\text { kejadian nyata atau sumber media }\end{array}$ & 75.47 & High \\
\hline & $\begin{array}{l}\text { Konsekuensi } \\
\text { menyebarka } \\
\mathrm{n} \text { informasi / } \\
\text { berita ke }\end{array}$ & $\begin{array}{l}\text { Tidak mengetahui resiko / konsekuensi } \\
\text { dalam menyebarkan informasi / berita di } \\
\text { media sosial }\end{array}$ & 66.67 & High \\
\hline
\end{tabular}




\begin{tabular}{|l|l|l|c|c|}
\hline & media sosial & & & \\
\hline Sikap & Afektif & $\begin{array}{l}\text { Senang membaca, mendengar informasi } \\
\text { yang mengandung ilegal konten }\end{array}$ & 59.76 & Medium \\
\cline { 2 - 4 } & Konotif & $\begin{array}{l}\text { Senang berbagi / menyebarkan informasi } \\
\text { tanpa mengetahui sumber dan asal usul } \\
\text { beritainformasi }\end{array}$ & 58,35 & Medium \\
\cline { 2 - 3 } & $\begin{array}{l}\text { Senang membicarakan informasi/berita } \\
\text { yang mengandung ilegal konten }\end{array}$ & & \\
\hline
\end{tabular}

\section{Analisa Dampak}

Tahap selanjutnya dari penilaian resiko adalah menetukan dampak atau tingkat resiko yang terjadi ketika ancaman berhasil di eksploitasi. Penilaian dampak didasarkan pada pertimbangan tingkat resiko. Berdasarkan potensi resiko, dampak terjadinya kejahatan ilegal konten dapat dikategorikan menjadi 3 jenis yaitu high, medium dan low. Tingkat dampak terjadinya kejahatan ilegal konten beserta indikatornya dapat dilihat pada tabel di bawah ini.Rujuk keSPNIST800-30definisirendah, menengah, dan tinggi.

\section{Penentuan Resiko}

Penentuan resiko dilakukan berdasarkan pada matrik resiko yang diturunkan dengan mengalikan potensi kemungkinan dengan nilai analisa dampak dari setiap ancaman (Driantami, n.d. : 2018). Matriks yang digunakan merupakan matriks $3 \times 3$ dengan rincian level resiko high, medium dan low. Berikut uraian tabel $3 \times 3$ level resikoberdasarkan Stoneburner Gary, Goguen Alice, 2002.Berdasarkan tingkat resiko ini dapat ditentukan jenis perlakuan atau tindakan yang harus dilakukan berdasrkan 3 jenis tingkatan resiko. Penilaian resiko didasarkan

pada matriks tingkatan resiko. Besaran peringkat dampak rendah (10), menengah (50),

Tabel 11 Penentuan Resiko

\begin{tabular}{|c|c|c|c|c|c|}
\hline No & Tindakan & Kemungkinan & Dampak & Level & Deskripsi Resiko \\
\hline 1 & $\begin{array}{l}\text { Ketidakmampuan dalam membedakan } \\
\text { informasi/berita yang mengandung ilegal } \\
\text { konten }\end{array}$ & \multirow[t]{3}{*}{ High } & \multirow[t]{3}{*}{$\begin{array}{l}\text { High } \\
100\end{array}$} & \multirow[t]{3}{*}{100} & \multirow[t]{3}{*}{ High } \\
\hline 2 & $\begin{array}{l}\text { Tidak menyertakan sumber dalam } \\
\text { merespon berita yang mengandung ilegal } \\
\text { konten }\end{array}$ & & & & \\
\hline 3 & $\begin{array}{l}\text { Tidak menyertakan pengetahuan yang } \\
\text { didapat dalam menyikapi informasi / } \\
\text { berita ilegal konten }\end{array}$ & & & & \\
\hline 4 & $\begin{array}{l}\text { Tidak mempertanyakan kebenaran } \\
\text { informasi dengan membandingkan } \\
\text { antara kejadian nyata atau sumber } \\
\text { media }\end{array}$ & $\begin{array}{r}\text { High } \\
1,0\end{array}$ & $\begin{array}{l}\text { Medium } \\
\quad 50\end{array}$ & 50 & Medium \\
\hline 5 & $\begin{array}{l}\text { Tidak mengetahui resiko / konsekuensi } \\
\text { dalam menyebarkan informasi / berita di } \\
\text { media sosial }\end{array}$ & $\begin{array}{l}\text { High } \\
1,0\end{array}$ & $\begin{array}{l}\text { High } \\
100\end{array}$ & 100 & High \\
\hline 6 & $\begin{array}{l}\text { Senang membaca, mendengar informasi } \\
\text { yang mengandung ilegal konten }\end{array}$ & $\begin{array}{c}\text { Medium } \\
0,5\end{array}$ & $\begin{array}{c}\text { Low } \\
10\end{array}$ & 50 & Medium \\
\hline 7 & $\begin{array}{l}\text { Senang berbagi / menyebarkan informasi } \\
\text { tanpa mengetahui simber dan asal usul } \\
\text { berita / informasi }\end{array}$ & \multirow[t]{2}{*}{$\begin{array}{c}\text { Medium } \\
0,5\end{array}$} & \multirow[t]{2}{*}{$\begin{array}{l}\text { Medium } \\
\quad 50\end{array}$} & \multirow[t]{2}{*}{50} & \multirow[t]{2}{*}{ Medium } \\
\hline 8 & $\begin{array}{l}\text { Senang membicarakan informasi/berita } \\
\text { yang mengandung ilegal konten }\end{array}$ & & & & \\
\hline
\end{tabular}

Pada tabel 10 diatas menunjukan penentuan resiko pada kejahatan ilegal konten.Tindakan pada nomor enam, tujuh dan delapan memiliki kemungkinan resiko menengah sebesar 0.5 yang selebihnya memiliki kemungkinan tinggi. Sedangkan pada nomor empat, tujuh dan delapan memiliki dampak resiko yang menengah sebesar 50 dan nomor 6 memiliki dampak resiko rendah sebesar 10 yang selebihnya memiliki dampak tinggi. Untuk level resiko pada nomor satu, dua, tiga, dan lima memiliki 
level resiko 100 yang nomor lain nya memiliki level resiko 50. Serta untuk deskripsi resiko pada nomor satu, dua, tiga, dan lima memiliki deskripsi resiko tinggi, yang selebihnya memiliki deskripsi resiko menengah. Kemungkinan yang dilakukan masyarakat dengan deskripsi.resiko tinggi adalah ikut menyebarkan berita hoax tersebut dan terpengaruh terhadap berita konten ilegal. Pada deskripsi resiko menengah kemngkinan yang dilakukan masyarakat adalah senang membaca serta mendengar informasi yang mengandung ilegal konten (hoax), tetapi tidak ikut menyebar luaskan konten ilegal tersebut, hanya sebagai penikmat pembaca.

\section{Rekomendasi Kontrol}

Rekomendasi kontrol didapat dari hasilpenilaian resiko dengan tujuan untukmengurangi tingkat resiko pada kejahatanilegal konten.

Tabel 12 Rekomendasi Kontrol

\begin{tabular}{|c|c|c|}
\hline Indikator & $\begin{array}{l}\text { Tingkat } \\
\text { Resiko }\end{array}$ & Rekomendasi Kontrol \\
\hline $\begin{array}{l}\text { Pengetahuan Tentang } \\
\text { Informasi }\end{array}$ & High & $\begin{array}{l}\text { 1. Memberikan pengetahuan atau ciri-ciri tentang } \\
\text { kejahatan ilegal konten } \\
\text { 2. Menyertakan pengetahuan yang didapat dari } \\
\text { sumber lain dalam merespon informasi yang } \\
\text { mengandung ilegal konten }\end{array}$ \\
\hline $\begin{array}{l}\text { Kemampuan mengenali } \\
\text { kridibilitas informasi }\end{array}$ & Medium & $\begin{array}{l}\text { 1. Kritis terhadap informasi / berita } \\
\text { 2. Melakukan perbandingan informasi / berita } \\
\text { dengan kejadian di dunia nyata ataumedia yang } \\
\text { memiliki kridibilitas. } \\
\text { 3. Jangan terlalu cepat mengambil keputusan } \\
\text { untuk meyebarkan atau meneruskan informasi } \\
\text { ke media sosial }\end{array}$ \\
\hline $\begin{array}{l}\text { Konsekuensi } \\
\text { menyebarkan informasi / } \\
\text { berita ke media sosial }\end{array}$ & High & $\begin{array}{l}\text { 1. Memahami UU ITE } \\
\text { 2. Mencantumkan sumber yang kridibel }\end{array}$ \\
\hline Afektif & Medium & $\begin{array}{l}\text { Jangan terlalu sering membaca / mendengar berita } \\
\text { yang mengandung konten ilegal }\end{array}$ \\
\hline Konatif & Medium & $\begin{array}{l}\text { 1. Jangan menyebarkan informasi yang diragukan } \\
\text { 2. Segera hapus informasi / berita yang diragukan }\end{array}$ \\
\hline
\end{tabular}

9. Hasil Dokumentasi

Tahap ini merupakan akhir dari Risk Assesment yang mendokumentasikan hasil dari penilaian risiko yangberupa profil risiko yang dapat mengurangi tingkat resiko pada kejahatan ilegal kenten.Yaitu :

Tabel 13 Hasil Dokumentasi

\section{Rekomendasi Kontrol}

1. Memberikan pengetahuan atau ciri-ciri tentang kejahatan ilegal konten

2. Menyertakan pengetahuan yang didapat dari sumber lain dalam merespon informasi yang mengandung ilegal konten

1. Kritis terhadap informasi / berita

2. Melakukan perbandingan informasi / berita dengan kejadian di dunia nyata ataumedia yang memiliki kridibilitas.

3. Jangan terlalu cepat mengambil keputusan untuk meyebarkan atau meneruskan informasi ke media sosial

3. Memahami UU ITE

4. Mencantumkan sumber yang kridibel

Jangan terlalu sering membaca / mendengar berita yang mengandung konten ilegal

1. Jangan menyebarkan informasi yang diragukan

2. Segera hapus informasi / berita yang diragukan 
Dari penilaian resiko yang dihasilkan bahwa terdapat dua tingkatan resiko dengan level tertinggi yaitu high level risk serta medium, hal ini dapat dilihat pada tabel 14

Tabel 14 Rekapitulasi resiko

\begin{tabular}{|l|l|l|l|l|}
\hline No & Ketegori & High & Medium & Low \\
\hline 1 & $\begin{array}{l}\text { Kemampuan } \\
\text { tentang informasi }\end{array}$ & Level risk 100 & & \\
\hline 2 & $\begin{array}{l}\text { Kemampuan } \\
\text { tentang mengenali } \\
\text { kridibilitas } \\
\text { informasi / berita }\end{array}$ & & Level risk 50 & \\
\hline 3 & $\begin{array}{l}\text { Pengetahuan } \\
\text { tentang konsekuensi } \\
\text { penyebaran } \\
\text { informasi }\end{array}$ & Level risk 100 & & \\
\hline 4 & Afektif & & Level risk 50 & \\
\hline 5 & Konatif & & Level risk 50 & \\
\hline
\end{tabular}

Pada tabel 14 di atas menunjukan rekapitulasi resiko dengan kategori pada nomor satu dan tiga memiliki tingkat level risk tinggi(100), sedangkan pada nomor dua, empat dan lima memliki tingkat level risk menengah (50).

Dari pembahasan di atas dapat disimpulkan bahwa :

1 Proses penilaian risiko (risk assessment) mendeskripsikan bahwa untuk tingkatan resiko tinggi (high) adalah pada aspek ketidakpahaman masyarakat akan konsekuensi menyebarkan informasi ilegal konten ke media sosial, untuk tingkatan resiko menengah (medium) pada aspek ketidakpemahaman masyarakat akan ciri informasi yang mengandung ilegal konten dan ketidak mampuan masyarakat dalam menilai kridibilitas serta senangnya masyrakat dalam berbagi informasi tanpa mengetahui kridibilitas informasi tersebut. terakhir untuk tingkatan resiko rendah (low) pada aspek akan senangnya masyarakat membaca informasi yang mengandung ilegal konten.

2 Berdasarkan pada hasil analisis yang dilakukan dengan likert scale maka dapat dikatakan bahwa dari dua puluh pernyataan yang disebarkan kepada enam puluh delapanresponden mempunyai pernyataan sangat setuju ada dua ratus lima puluh delapan, setuju ada empat ratus sepuluh, netral tiga ratus delapan puluh tujuh, tidak setuju dua ratus enam dan sangat tidak setuju ada sembilan puluh sembilan.

\section{KESIMPULAN}

Berdasarkan hasil dan pembahasan yang telah dilakukan dengan menggunakan metode NIST 800 30, maka dapat di simpulkan sebagai berikut :

1. Semakin besarnya jumlah pengguna internet dan dengan mudahnya mendapatkan informasi saat ini menjadikan berita hoax semakin dengan mudah tersebar.

2. Aturan dan pasal untuk menjerat hukuman bagi penyebar hoax belum mampu mengendalikan jumlah berita hoax yang terus terproduksi setiap waktu.

3. Biasanya budaya-budaya pada negara yang sudah melek internet/media sosial membuat berita hoax semakin mudah tersebar.

\section{REFERENSI}

Abidin, D.Z., 2015. Kejahatan dalam Teknologi Informasi dan Komunikasi. J. Ilm. Media Process. 10, 1-8.

Alatas, M.Y., Mursalin, M., Andriasnyah, A., Prasetyo, A., Hardianto, D., Dewi, R.M., 2018. Sikap Dan Persepsi Konsumen Terhadap Merek Jilbab Syafirah Muslimah Di Tangerang Selatan: Pendekatan Semantic Differential. Indones. J. Econ. Appl.1,1-9.

Danuri, M., suharnawi, 2018. Trend cyber crime dan teknologi informasi di indonesia. Infokam 2, 55-64.Driantami, H.T.I., n.d. Analisis Risiko Teknologi Informasi Menggunakan 
ISO 31000 (Studi kasus: Sistem Penjualan PT Matahari Department Store Cabang Malang Town Square).

Elanda, A., Tjahjadi, D., 2018b. Analisis Manajemen Resiko Sistem Keamanan Ids (Intrusion Detection System) Dengan Framework Nist (National Institute of Standards and Technology) Sp 800-30 (Studi Kasus Disinfolahtaau Mabes Tni $\mathrm{Au})$ Infoman's 12, 1-13. https://doi.org/10.33481/infomans.v12i1.45

Gary Stoneburner, Alexis Feringa, Alice Goguen, 2002. Risk Management Guide for Information Technology Systems, and Underlying Technical Models for Info. Technology Security. Diane Publishing Company.

Hikmat, M., 2011. Metode Penelitian. Graha Ilmu, Yogyakarta.

Rahadi, D.R., 2017. PERILAKU PENGGUNA DAN INFORMASI HOAX DI MEDIA SOSIAL. J. Manaj. DAN KEWIRAUSAHAAN. https://doi.org/10.26905/jmdk.v5i1.1342

Raodia, R., 2019. Pengaruh Perkembangan Teknologi Terhadap Terjadinya Kejahatan Mayantara (Cybercrime). Jurisprud. Jur. Ilmu Huk. Fak. Syariah Dan Huk. 6, 39.

Ratnamulyani, I.A., Maksudi, B.I., 2018. PERAN MEDIA SOSIAL DALAM PENINGKATAN PARTISIPASI PEMILIH PEMULA DIKALANGAN PELAJAR DI KABUPATEN BOGOR. Sosiohumaniora 20. https://doi.org/10.24198/sosiohumaniora.v2 $0 \mathrm{i} 2.13965$

Yulianita, N., Nurrahmawati, N., Wiwitan, T., 2017. PEMAHAMAN DOSEN UNIVERSITAS ISLAM BANDUNG TENTANG MAKNA HOAX DI MEDIA SOSIAL WHATSAPP.
WACANA J. Ilm. Ilmu Komun. 16, 237. https://doi.org/10.32509/wacana.v16i2.18

\section{PROFIL PENULIS}

Ahmad Marsehan, M.Kom. Tahun 2015 lulus dari Program Strata Satu (S1) Program Studi Teknik Informatika Sekolah Tinggi Manajemen Informatika dan Komputer Musi Rawas dan Tahun 2020 lulus dari Program Magister (S2) di Universitas Bina Darma Palembang. 